\title{
Biomass Straw Based Activated Porous Carbon Materials for High-Performance Supercapacitors
}

\author{
Mengdie GUAN, Xinle ZHANG, Yingping WU, Qihao SUN, Dongqi DONG, Xiaoling ZHANG, \\ Jie WANG*
}

College of Chemistry and Pharmaceutical Sciences, Qingdao Agricultural University, Qingdao, China

*Corresponding Author: Jie WANG, Changcheng Road 700\#, Chengyang District, Qingdao, 266109, China; wangjie@qau.edu.cn

\begin{abstract}
:
Biomass straws are often regarding as agricultural waste, usually burned off in rural areas, which results in severe resource waste and air pollution. In this work, biomass-based porous carbon material with a lamellar microstructure is obtained via simple hydrothermal and subsequent $\mathrm{KOH}$ activation, the optimum activate process is determined by the proportion of activator. Scanning electron microscopy (SEM) and nitrogen adsorption techniques are conducted to investigate the physical properties of the materials. Cyclic voltammetry and constant current discharge/charge in the three-electrode system and symmetrical double-layer capacitors results

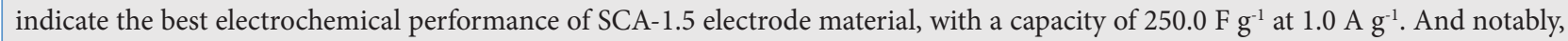
high recycling stability at a high cycling rate of $1.0 \mathrm{~A} \mathrm{~g}^{-1}$ after 18,000 cycles.

Keywords: straw; biomass carbon; activation; porous lamellar structure; supercapacitor.
\end{abstract}

\section{Introduction}

The continuous consumption of fossil fuels has caused severe globally environmental pollution and resource depletion. Thus, research and development of renewable energy has attracted world-wide attention ${ }^{[1-4]}$. Many clean energy resources such as solar energy, tidal energy, wind energy are readily available and inexhaustible. Still, they possess low conversion efficiency, unbalanced power output, and hard to move and storage, which limited their applications in vehicles, portable devices, and other areas dramatically. Therefore, developing clean energy storage devices is of vital importance to potentially solve the problems. Feature of high energy density and fast discharge/charge rate, supercapacitors, has attracted worldwide attention ${ }^{[7-14]}$. The carbon-based supercapacitors also can be called the double electric layer capacitor. Such a device is potentially applied in energy storage devices because the capacity is significantly higher than traditional capacitors, and the output voltage is more stable than pseudocapacitors ${ }^{[15,16]}$. The mechanism of electric double-layer capacitors is mostly based on the Herm Holtz principle ${ }^{[17-19]}$. An ideal capacitor material often needs a specific surface area as large as possible to serve a high capacity and conductivity, such as carbon nanotubes, graphene, carbon-based aerogels, etc.
In the industrial producing process, the cost of raw materials is an essential point for practical application. The raw materials from carbon nanotubes, graphene, carbonbased aerogels are not economically friendly, which limited the mass production of the related products ${ }^{[20,21]}$. This project selected agricultural wastes (biomass straw) as raw materials, produced high capacity and stability carbonbased electrode materials via simple hydrothermal and subsequent $\mathrm{KOH}$ activation method. Such a template-free and the surfactant-free process are potentially applicable for industrial constructing.

\section{Experimental Section}

\subsection{Materials synthesis}

Selected the air-dried bio-straw, separated the skin and transferred the core into a $100 \mathrm{~mL}$ Teflon-lined stainless steel autoclave, raised the temperature to $200^{\circ} \mathrm{C}$ and kept for $2 \mathrm{~h}$. After cooled down to room temperature, the pre-carbonized materials were divided into five parts (2 $\mathrm{g}$ per part, approximately), added into solid $\mathrm{KOH}$ with the proportion by mass in 1:0.0, 1:0.5, 1:1.0, 1:1.5, 1:2.0, respectively. Then mixed in agate mortars thoroughly, transfer the mixture into the tubular furnace at a heating rate of $5{ }^{\circ} \mathrm{C} \mathrm{min}^{-1}$ to $900{ }^{\circ} \mathrm{C}$ in nitrogen atmosphere and 
kept $2 \mathrm{~h}$ for activation. Cleaned the activated materials to neutral with deionized water and dried with air-dried oven to obtain the bio-straw-based carbon material. According to the proportion of activator, the five parts of materials are denoted as SCA-0, SCA-0.5, SCA-1.0, SCA-1.5, SCA-2.0, respectively.

\subsection{Physical characterization}

The micromorphology of the material was characterized by SEM (JSM-7500f), and the specific surface area and pore diameter of the materials were detected by the surface area analyzer (NOVA 2200e).

\subsection{Electrochemical Measurements}

The capacitors were assembled by using active materials, carbon black and PVDF at a proportion of 8:1:1 (respectively, by mass), respectively. Mixed and separated those materials in agate mortars, then applied in nickel foams and dried the nickel foam in a bake oven at $80^{\circ} \mathrm{C}$ for $2 \mathrm{~h}$. Cyclic voltammogram (CV) and discharge/charge measurements via a three-electrode system by electrochemical workstation were conducted to investigate the electrode activity. In the three-electrode system, saturated calomel electrode (SCE), carbon rod electrode, and $3 \mathrm{M} \mathrm{KOH}$ solution were served as reference electrode, counter electrode, and electrolyte, respectively.

\section{Results and discussion}

\subsection{Structure and morphology analysis}

Figure 1 presents the SEM image of SCA-0 and SCA-1.5. Without $\mathrm{KOH}$ activation, the smooth lamellar structure of SCA-0 (Figure 1a-b) can provide a large specific surface area. After $\mathrm{KOH}$ activated, the smooth surface turns rough, which indicates the active region was enlarged, the porous microstructure (Figure 1c-d) makes the electrolyte access into the pores easier. According to the discussion above, the $\mathrm{KOH}$ activator does not change the micromorphology of the materials significantly; thus, the activation process will not cast down the electrochemical stability as well.

Figure 2 exhibits the nitrogen adsorption-desorption curves (BET) of materials with different activator proportions. All four materials have hysteresis rings in the range of $\mathrm{P} / \mathrm{P}_{0}=0.5 \sim 0.8$. Among them, SCA-1.5 is the most obvious, indicates the material has an excellent mesoporous structure. Table 1 shows the specific surface area and pore size distribution of the four materials from the BET test, in which SCA-1.5 has the highest specific surface area (177.0 $\left.\mathrm{m}^{2} \mathrm{~g}^{-1}\right)$, much higher than the other three materials. The relative lower specific surface area of SCA- 0.5 and SCA1.0 may be attributed to insufficient $\mathrm{KOH}$ activator. SCA2.0 loses the original structure, perhaps attributed to the excessive $\mathrm{KOH}$ activator caused over-activation. From the pore size distribution, the average pore size of SCA-1.5 is $3.1 \mathrm{~nm}$, which is smaller than the other three materials. It indicates that the $\mathrm{KOH}$ activator constructed microholes successfully in the lamellar carbon materials, which is consistent with the conclusion of SEM analysis. The detailed $\mathrm{KOH}$ activation mechanism is as follows ${ }^{[22,23]}$ :
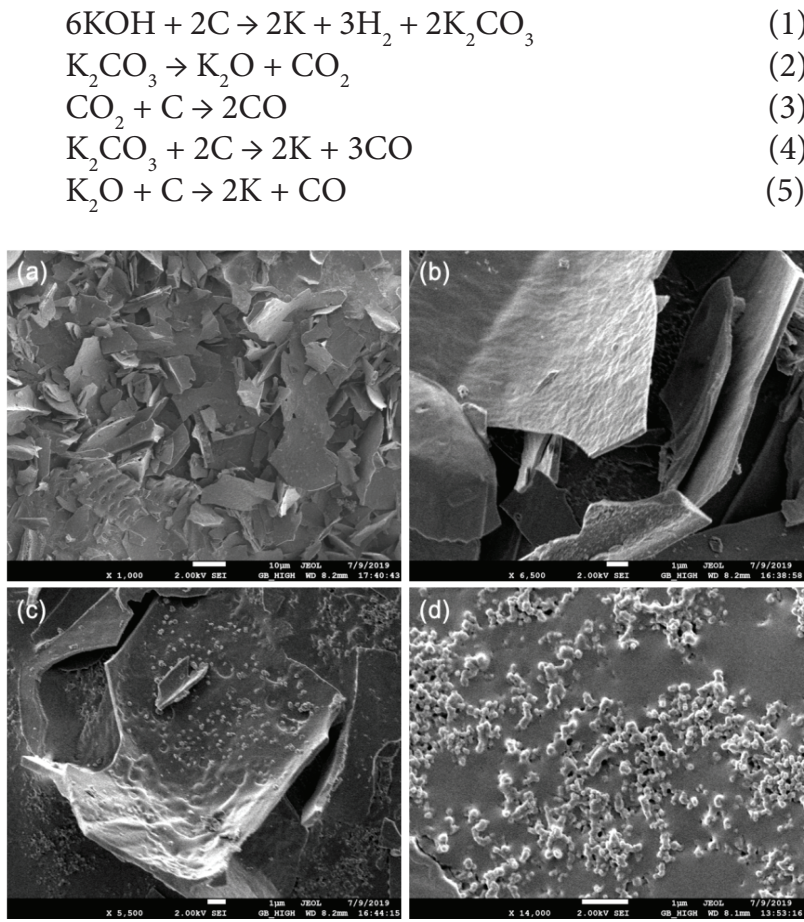

Figure 1 (a-b) SEM images of SCA- 0 with step-by-step magnify; (c) SEM image of SCA-1.5 and the magnification image.

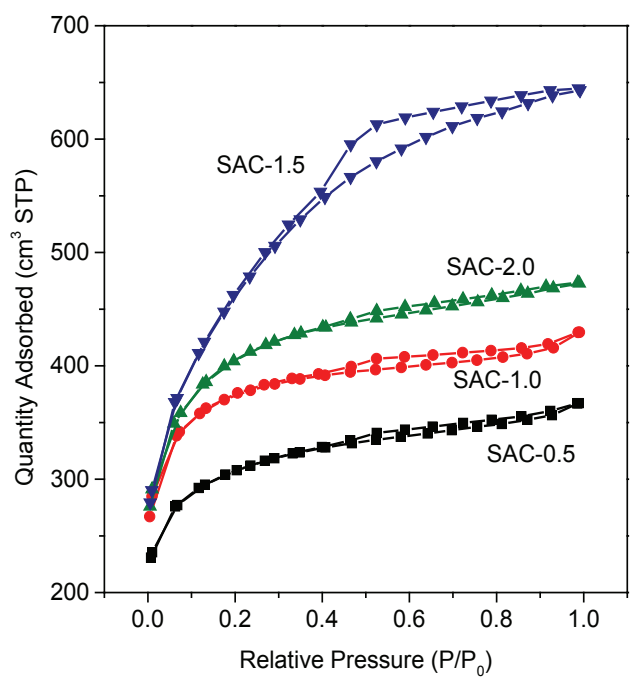

Figure 2 The $\mathrm{N}_{2}$ desorption curves of the four activated materials.

Table1 Surface area and pore size distribution of the four different active materials.

\begin{tabular}{ccc}
\hline Samples & $\begin{array}{c}\mathrm{S} \\
\left(\mathrm{m}^{2} \mathrm{~g}^{-1}\right)\end{array}$ & $\begin{array}{c}\text { Pore } \\
\text { Size }(\mathrm{nm})\end{array}$ \\
\hline SCA-0.5 & 33.7 & 3.5 \\
SCA-1.0 & 44.0 & 3.5 \\
SCA-1.5 & 177.0 & 3.1 \\
SCA-2.0 & 73.3 & 3.5 \\
\hline
\end{tabular}




\subsection{Electrochemical Performance}

Figure 3a exhibits the CV curves of each activated electrode material in a $3 \mathrm{M} \mathrm{KOH}$ solution with a scanning rate at 50 $\mathrm{mV} \mathrm{s}^{-1}$. The electrode of SCA-1.5 material has the largest double electric layer capacity, and the CV curves exhibit a rectangular shape in the voltage of $-1.0-0.2 \mathrm{~V}$, which is close to the shape of ideal double electric layer capacitors. In comparison, the electrode of SCA-0 material has a lower double layer capacity in the potential range of -0.4-0.2 V, indicating that the activation process significantly enlarged the materials' surface area. The electrode of SCA-0, SCA0.5 , SCA-1.0, SCA-1.5 and SCA-2.0 materials contains $36.0,100.2,128.4,141.0$ and $83.8 \mathrm{~F} \mathrm{~g}^{-1}$, respectively (Figure $3 \mathrm{~b})$. Therefore, the electrode of SCA-1.5 material has the optimal activator proportion for the biomass carbon-based materials. The CV curves with different scanning rates were exhibited in Figure 3c. When the scanning rate above 200 $\mathrm{mV} \mathrm{s}^{-1}$, the material almost remains a regular rectangular shape, which indicates the material has a good rate capability. The capacitance line chart (Figure $3 \mathrm{~d}$ ) processed from the $\mathrm{CV}$ curve showed that with the scanning rate increases, the capacitance of SCA-1.5 material decreased significantly but remains $120.0 \mathrm{~F} \mathrm{~g}^{-1}$ at a scan rate of $200 \mathrm{mV} \mathrm{s}^{-1}$, primarily
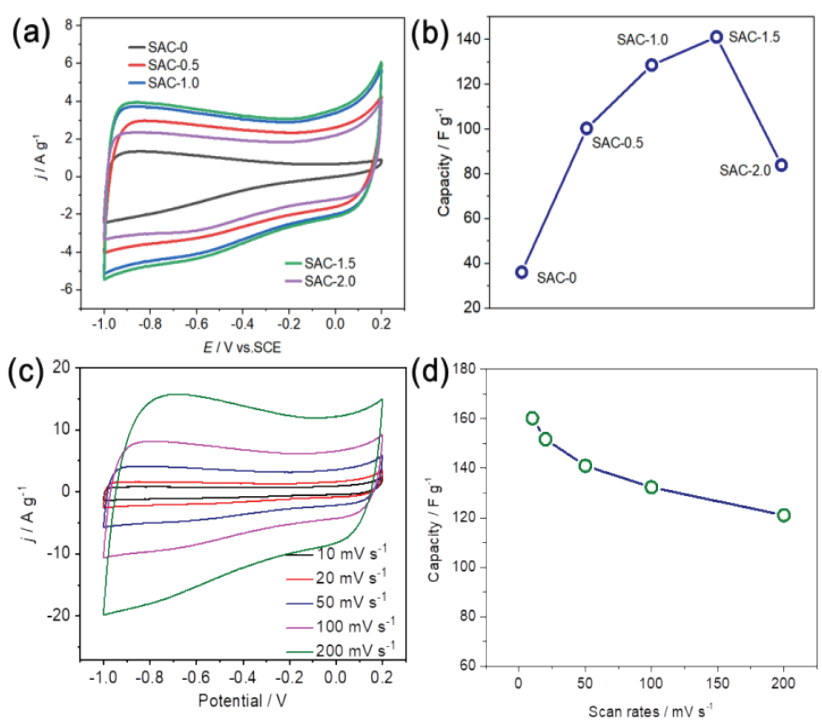

Figure 3 (a) CV curves of different activated materials, scan rate at $50 \mathrm{mV} \mathrm{s}^{-1}$ and the corresponding line chart of capacity (b); (c) CV curves of SAC-1.5 material at different scan rates and the corresponding line chart of capacity (d)

\section{Conclusions}

This project adopted the hydrothermal method-KOH activation process, for a biomass-based carbon material with a lamellar porous microstructure. The optimized activation process was conducted by adjusts the activator proportion. SCA-1.5 has the best electrochemical performance, the specific capacitance at $250.0 \mathrm{~F} \mathrm{~g}^{-1}$, with indicates the excellent capacitance performance.

Figure 4a exhibits the discharge/charge performance of four electrode materials with different activator proportions. SAC-1.5 has the best discharge duration with a $1.2 \mathrm{~V}$ potential window. The corresponding line chart of capacity (Figure $4 \mathrm{~b}$ ) demonstrates that SAC-1.5 material possesses a capacity of $311 \mathrm{~F} \mathrm{~g}^{-1}$, which is much higher than SAC-0.5 $\left(212 \mathrm{f} \mathrm{g}^{-1}\right)$, SAC-1.0 $\left(247 \mathrm{~F} \mathrm{~g}^{-1}\right)$ and SAC-2.0 (183 F $\mathrm{g}^{-1}$ ) and consistent with the CV curve analysis.

Considering the electrochemical behavior is often different from the ideal conditions, we assembled a symmetrical double-layer capacitor based on SAC-1.5 material and tested the electrochemical performance. Figure $4 \mathrm{c}$ exhibits the initial capacitance of the capacitor is $65 \mathrm{~F} \mathrm{~g}^{-1}$ at the discharge/charge rate of $1 \mathrm{~A} \mathrm{~g}^{-1}$. After 2000 cycles activation, the capacity increased to $77 \mathrm{~F} \mathrm{~g}^{-1}$. After 18000 cycles, the capacity remains stable, indicates that the SCA-1.5 based double-layer capacitor possesses excellent discharge/charge stability. Besides, this biomassbased supercapacitor lighted up a 2.2 V LED series, which combined with 28 bulbs successfully, proves the bio-straw based carbon materials are potentially applicable in the energy storage devices.
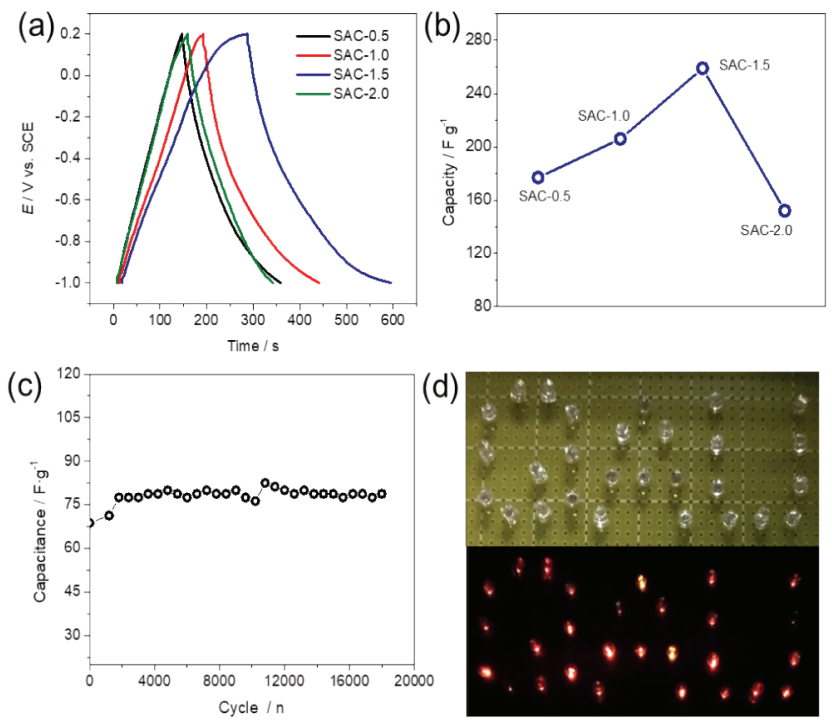

Figure 4 (a) Discharge/charge curves of different activated materials at current density of $1 \mathrm{~A} \mathrm{~g}^{-1}$ and the corresponding line chart of capacity (b); (c) Discharge/charge curves of SAC-1.5 based supercapacitor device at $1 \mathrm{~A} \mathrm{~g}^{-1}$; (d) Lighting LED series powered by SAC-1.5 based supercapacitor device.

the current density at $1.0 \mathrm{~A} \mathrm{~g}^{-1}$. Besides, such electrode remained stable even after 18000 cycles at a high cycling rate of $1.0 \mathrm{~A} \mathrm{~g} \mathrm{~g}^{-1} \mathrm{e}$. The raw material of this project is cheap and easy to access, which potentially applied in the energy storage devices and for mass production. With an excellent electrochemical activity and stability, proves that the biostraw based supercapacitors have a promising prospective application. 
Author Contributions: J.W. conceived and designed the experiments. M.G., X.Z., Y.W. Q.S. and D.D. performed the materials synthesis. M.G. performed the electrochemical characterizations. J.W., X.Z. and D.D. wrote the manuscript. All authors discussed the results and commented on the manuscript.

Conflict of Interest: The authors declare that there is no conflict of interest regarding the publication of this paper.

Acknowledgments: This work was supported by the Research Foundation for Distinguished Scholars of Qingdao Agricultural University (665-1119008). The authors thank the Central Laboratory of Qingdao Agriculture University for the physical characterization.

\section{References}

[1] Dhillon, R.; Wuehlisch, G. Mitigation of global warming through renewable biomass. Biomass Bioener. 2013, 48, 75-89.

[2] Burke, A. Ultracapacitors: why, how, and where is the technology. J. Power Sources, 2000, 91, 37-50.

[3] Xue, J. T.; Wu, Y.; Dai, Y.; Xia, Y. Electrospinning and Electrospun Nanofibers: Methods, Materials, and Applications. Chem. Rev., 2019, 119, 5298-5415.

[4] Yang, H.; Liu, S.; Cao, L.; Jiang, S.; Hou, H. Superlithiation of non-conductive polyimide toward high-performance lithium-ion batteries. J. Mater. Chem. A, 2018, 6, 2121621224.

[5] Vix-Guterl, C.; Frackowiak, E.; Jurewicz, K.; Friebe, M.; Parmentier, J.; Béguin, F. Electrochemical energy storage in ordered porous carbon materials. Carbon, 2005, 43, 1293-1302.

[6] Liu, C.; Li, F.; Ma, L. P.; Cheng, H. M. Advanced Materials for Energy Storage. Adv. Mater., 2010, 22, E28-E62.

[7] Gu, W.; Yushin, G. Review of nanostructured carbon materials for electrochemical capacitor applications: advantages and limitations of activated carbon, carbidederived carbon, zeolite-templated carbon, carbon aerogels, carbon nanotubes, onion-like carbon, and graphene. WIRES Energy Environ. 2014, 3, 424-473.

[8] Zhang, L.L.; Zhao X. Carbon-based materials as supercapacitor electrodes. Chem. Soc. Rev. 2009, 38, 2520-2531.

[9] Wang,W.; Shi,Y.; Su,Y.; Wang,Y.; Sun, H. Construction of $\mathrm{MnO}_{2}$ Nanowire for a High-Performance Lithium Ion Supercapacitor. Research and Application of Materials Science 2019, 1, 18-23.

[10] Xu, W., Ding, Y., Yu, Y., Jiang, S., Chen, L., \& Hou, H. Highly foldable PANi@CNTs/PU dielectric composites toward thin-film capacitor application. Mater. Lett., 2017, 192, 25-28.
[11] Wang, X.; Lu, X.; Liu, B.; Chen, D.; Tong, Y.; Shen, G. Flexible energy-storage devices: design consideration and recent progress. Adv. Mater., 2014, 26, 4763-4782.

[12] Zhang, Q.; Uchaker, E.; Candelaria, S. L.; Cao, G. Nanomaterials for energy conversion and storage. Chem. Soc. Rev., 2013, 42, 3127-3171.

[13] Mao, X.; Hatton, T. A.; Rutledge, G. C. A review of electrospun carbon fibers as electrode materials for energy storage. Curr. Org. Chem., 2013, 17, 1390-1401.

[14] Dai, L.; Chang, D. W.; Baek, J. B.; Lu, W. Carbon nanomaterials for advanced energy conversion and storage. Small 2012, 8, 1130-1166.

[15] Ogoshi, T.; Sueto, R.; Yoshikoshi, K.; Sakata, Y.; Akine, S.; Yamagishi, T. A. Host-guest complexation of perethylated pillar [5] arene with alkanes in the crystal state. Angew. Chem. Int. Ed. 2015, 54, 9849-9852.

[16] Hulicova-Jurcakova, D.; Seredych, M.; Lu, G. Q.; Kodiweera, N. K. A. C.; Stallworth, P. E.; Greenbaum, S.; Bandosz, T. J. Effect of surface phosphorus functionalities of activated carbons containing oxygen and nitrogen on electrochemical capacitance. Carbon, 2009, 47, 15761584.

[17] Ma, H.; Zhou, Q.; Wu, M.; Zhang, M.; Yao, B.; Gao, T.; ... Shi, G. Tailoring the oxygenated groups of graphene hydrogels for high-performance supercapacitors with large areal mass loadings. J. Mater. Chem. A 2018, 6, 6587-6594.

[18] He, S.; Chen, W. 3D graphene nanomaterials for binderfree supercapacitors: scientific design for enhanced performance. Nanoscale 2015, 7, 6957-6990.

[19] H. Jing-quan, L. Kai-yue, Y. Yi-ying, et al. Synthesis and electrochemical performance of flexible cellulose nanofiber-carbon nanotube/natural rubber composite elastomers as supercapacitor electrodes[J]. New Carbon Mater. 2018, 33, 341-350.

[20] Farma, R.; Deraman, M.; Awitdrus, A.; Talib, I. A.; Taer, E.; Basri, N. H.; ... Hashmi, S. A. Preparation of highly porous binderless activated carbon electrodes from fibres of oil palm empty fruit bunches for application in supercapacitors. Bioresource Technol. 2013, 132, 254 261.

[21] Inagaki, M.; Kim, Y.A.; Endo. M. Graphene: preparation and structural perfection. J. Mater. Chem. 2011, 21 , 3280-3294.

[22] Wang, J.; Kaskel, S. KOH activation of carbon-based materials for energy storage. J. Mater. Chem., 2012, 22, 23710-23725.

[23] Bhattacharjya, D.; Yu, J. Activated carbon made from cow dung as electrode material for electrochemical double layer capacitor. J. Power Sources, 2014, 262, 224-231. 